\title{
Introduction to the March Issue of Oceanography
}

Welcome to the March issue of Oceanography. In this issue, instead of focusing on one theme or topic in a special invited section, five feature articles cover an extraordinarily broad range of subjects that for the most part came to us via unsolicited manuscript submission. We are also very excited to introduce a new department called DIY Oceanography, where authors share all relevant information about a homemade sensor, an instrument, or new software so that others can build, or build upon, it.

The March issue kicks off with a bit of history. Baker and Zall describe the origins and impacts of the MEDEA program, launched in 1992, that resulted in declassification of huge amounts of data collected by the US Intelligence and Defense Communities that could enhance research on Earth's environment. One of the most widely recognized outcomes of the MEDEA program is the global map of ocean bottom topography produced by Walter Smith and David Sandwell based on GEOSAT altimeter data that were declassified during MEDEA.

The MEDEA retrospective is followed by a contribution from Royer and Finney that provides an "oceanographic perspective" on early human migrations to the Americas. Adding to the discussion of this much written about subject, the authors discuss ocean currents and sea levels that likely existed during and after the Last Glacial Maximum that could have enhanced or hindered boat journeys along the route from Berengia, which included parts of what are now Alaska and eastern Siberia, to the Pacific Northwest.

The ISMAR Team analyzes the different factors that led up to the 2019 great flooding of Venice and shows why it was unlikely that an accurate forecast could have been developed for this event. Coastal regions around the world are facing similar situations, which may worsen in the future. The authors suggest that scientists working on such problems should exchange ideas and information to improve local solutions.

Cusick et al. provide details about how they developed and executed their citizen science project that partners scientists with the Antarctic tourism industry to enable regular data collection in coastal waters from November to March. In this inspiring article, the authors show how using an untraditional approach for gathering data can enhance research in Antarctica and also educate tourists about the polar environment.

The final feature article in this issue by Greengrove et al. provides an overview of current Ocean Observatories Initiative (OOI) educational resources and opportunities, along with example applications of OOI data. The authors invite the community to create and share new ways to engage students with OOI data.
The March Oceanography department contributions are also varied. They include a commentary that champions the continuing need for organizations that support the bottom-up development and nurturing of science ideas (Urban et al.) and another that describes a student-led research cruise and the insights the students gained from the experience at their stage of graduate education (Bisson et al.). A report by Dierssen et al. details the recommendations of a recent workshop on data needs for hyperspectral detection of algal diversity, and a hands-on oceanography contribution by Gravinese et al. provides three activities in which undergraduates can use real data to understand how climate and oceanographic conditions have impacted coral reef growth over the last 5,000 years.

The kick-off DIY contribution by Haëntjens and Boss introduces Inlinino, an open-source software data logger with realtime visualization capabilities whose main purpose is to log scientific measurements collected at sea over extended periods. In line with the mission of DIY Oceanography, anyone with moderate coding skills should be able to add new sensors.

The March issue also contains our usual education, Ripple Marks, and careers columns.

For those who only receive electronic copies of Oceanography, don't forget that along with the March issue, we publish the annual ocean exploration supplement that details the latest E/V Nautilus, NOAA Ship Okeanos Explorer, and R/V Falkor field seasons. The supplement-now in its tenth year-is mailed with hard copies of the March issue to TOS members and is also available online on the Oceanography website (https://tos.org/ ocean-exploration).

It's been an astonishing seven years since Oceanography has published an issue without a special section devoted to one theme or one program. While we don't know when the next one will be, we strongly encourage continued submission of articles that are of broad interest to the oceanographic community; those articles can be published in any issue, special or not. See the Oceanography author guidelines (https://tos.org/ oceanography/guidelines) or drop me or any editorial board member a note (email addresses available here: https://tos.org/ oceanography/editors) with an idea for an article. We look forward to hearing from you!

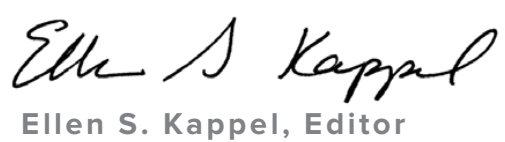

Oceanography | March 2020

5 